\title{
Biópsia e teste de contratura muscular
}

\author{
In vitro contracture test
}

\section{Helga Cristina Almeida da Silva}

CEDHIMA (Centro de Estudo, Diagnóstico e Investigação de Hipertermia Maligna). Departamento de Anestesiologia, Dor e Terapia Intensiva - Escola Paulista de Medicina, Universidade Federal de São Paulo (UNIFESP). Rua Napoleão de Barros, 715 - $5^{\circ}$ andar - Vila Clementino, CEP 04024-002 - São Paulo/SP, Brasil. Telefone/FAX: 55 (11) 5571-2746 - 55 (11) 5576-4069. E-mail address: cedhima@hotmail.com.

O principal objetivo da avaliação laboratorial nos pacientes suspeitos de hipertermia maligna anestésica (HMA) é o de investigar a suscetibilidade dos que sobrevivem à crise, assim como de seus familiares.

O método mais confiável para determinar a suscetibilidade à HMA é o estudo da contratura do músculo in vitro em presença de halotano e cafeína (in vitro contracture test IVCT), havendo positividade a pelo menos uma das duas substâncias em praticamente 100\% dos sobreviventes de um episódio de hipertermia maligna anestésica. Nesse teste, um fragmento de biópsia muscular é conectado a um transdutor que afere o grau de contração muscular; o músculo é, então, exposto a dose única ou crescente de cafeína e/ou halotano. A diferença entre a resposta do músculo de indivíduos normais e dos pacientes suscetíveis está no grau de contração alcançado e na sua sensibilidade à cafeína e ao halotano. Atualmente existem dois protocolos básicos para a interpretação do teste: o protocolo norte-americano e o protocolo europeu, que é aquele empregado no CEDHIMA. O protocolo europeu considera suscetíveis os pacientes com resposta anormal às duas substâncias (MHS), equívocos (MHE) os que responderam de forma anormal só a uma delas, e negativos (MHS) os que não responderam de forma anormal a nenhuma das duas substâncias.

O CEDHIMA investigou 70 pacientes, cujas indicações foram: HMA (42), doença neuromuscular (10) e síndrome neuroléptica maligna (4); 14 eram controles periódicos. No grupo teste de 56 pacientes, a média de idade foi de 43 anos (14-84); havia 27 homens e 29 mulheres. No IVCT, 23 pacientes foram negativos para hipertermia maligna (MHN) e 47 foram suscetíveis (MHE/MHS). No grupo MHS/MHE, 12\% apresentavam aumento dos níveis séricos de CPK, 4 pacientes apresentavam alterações na biópsia muscular compatíveis com doença central core (CCD) e 2, multiminicores (MMC). 


\section{Referências}

1. Ellis FR, Halsall PJ, Ording H ET AL. A protocol for the investigation of malignant hyperpyrexia (MH) susceptibility. Br J Anaesth 1984; 56:1267-1269.

2. Kozak-Reiss G, Coursange F, Aubert M. Hyperthermies Malignes. In: Encyclopedie Medicochirurgicale. Techniques Chirurgicales. Anesthésie - Reanimation, Paris, Ed. Techniques, $36412 \mathrm{E}^{10}$, 1991, p 1-18.

3. Larach MG. Should we use muscle biopsy to diagnose malignant hyperthermia susceptibility? Anesthesiol 1993; 79:1-4.

4. Ørding, $\mathrm{H}$ for The European Malignant Hyperthermia Group. In vitro contracture test for the diagnosis of malignant hyperthermia following the protocol of the European MH Group: results of testing patients surviving fulminant $\mathrm{MH}$ and unrelated low-risk subjects. Acta Anaesthesiol Scand 1997; 41:955-966. 